\title{
Zn-doped etch-and-rinse model dentin adhesives: Dentin bond integrity, biocompatibility, and properties
}

\author{
Daphne Câmara Barcellos ${ }^{a}$, Beatriz Maria Fonseca ${ }^{b}$, César Rogério Pucci ${ }^{c}$, \\ Bruno das Neves Cavalcanti ${ }^{d}$, Erasmo De Souza Persici ${ }^{e}$, \\ Sérgio Eduardo de Paiva Gonçalves ${ }^{c, *}$ \\ a São José dos Campos School of Dentistry, Department of Restorative Dentistry, UNESP - Uniu Estadual Paulista, \\ São José dos Campos, SP, Brazil \\ b Clinical Research Academic Group, Institute of Science and Technology, UNESP - Univ Estadual Paulista, \\ São José dos Campos, SP, Brazil \\ c Department of Restorative Dentistry, UNESP - Univ Estadual Paulista, São José dos Campos, SP, Brazil \\ d Department of Cariology, Restorative Sciences and Endodontics, School of Dentistry - University of Michigan, USA \\ e Electrical System, Embraer Defense and Security, Brazil
}

\section{A R T I C L E I N F O}

\section{Article history:}

Received 25 September 2015

Received in revised form

15 April 2016

Accepted 23 April 2016

Keywords:

Dental adhesive

Dentin-bond agents

Zinc oxide

Methacrylates

Matrix metalloproteinase inhibitors

Collagen

\begin{abstract}
A B S T R A C T
Objective. This study assessed a 6 month resin/dentin bond's durability and cytotoxic effect of $\mathrm{Zn}$-doped model dentin adhesives. The mechanical and physicochemical properties were also tested.

Methods. A model etch-and-rinse single-bottle adhesive was formulated ( $55 \mathrm{wt} . \%$ Bis-GMA, 45 wt.\% HEMA, 0.5 wt.\% CQ, 0.5 wt.\% DMAEMA) and Zinc methacrylate (Zn-Mt) or ZnO nanoparticles ( $\mathrm{ZnOn}$ ) were added to the model's adhesive, resulting in three groups: Group Control (control model adhesive); Group Zn-Mt (1 wt.\% Zn-Mt incorporated to adhesive) and Group ZnOn (1 wt.\% ZnOn incorporated to adhesive). The microtensile bond strength (mTBS) was assessed after $24 \mathrm{~h}$ or 6 months in water storage. Mechanical properties (diametral tensile strength/DTS, flexural strength/FS, flexural modulus/FM, resilience modulus/RM, and compressive strength/CS) and physicochemical properties (polymerization shrinkage/PS, contact angle/CA, water sorption/WS, and water solubility/WS) were also tested. Cytotoxicity was evaluated with SRB biochemical assay.

Results. No significant difference in the DTS, FS, FM, CS, CA, WS, and WS were found when $1 \%$ of $\mathrm{ZnOn}$ or $\mathrm{Zn}$-Mt was added to the model dentin adhesive. Group Zn-Mt decreased the RM of adhesive. Groups $\mathrm{Zn}-\mathrm{Mt}$ and $\mathrm{ZnOn}$ decreased the PS of adhesives. Group ZnOn reduced the cytotoxicity of adhesive. Group ZnOn preserved mTBS after 6 months storage without degradation areas as seen by SEM analysis.
\end{abstract}

\footnotetext{
* Corresponding author at: Avenida Engenheiro Francisco José Longo, 777, Jardim São Dimas, São José dos Campos, SP, CEP: 12245-000, Brazil. Tel.: +55 123947 9051; fax: +55 1239479010 .

E-mail address: sergio@fosjc.unesp.br (S.E.d.P. Gonçalves).

http://dx.doi.org/10.1016/j.dental.2016.04.003

0109-5641/@ 2016 The Academy of Dental Materials. Published by Elsevier Ltd. All rights reserved.
} 
Significance. The $1 \mathrm{wt} . \% \mathrm{ZnOn}$ may preserve the integrity of the hybrid layer and may reduce cytotoxicity and polymerization shrinkage of model dentin adhesive. The addition of $\mathrm{Zn}-\mathrm{Mt}$ to the adhesive had no beneficial effects.

( 2016 The Academy of Dental Materials. Published by Elsevier Ltd. All rights reserved.

\section{Introduction}

The lack of durable dental adhesives is considered one of the main problems with the use of composite materials in dentistry. Failures of composite restorations are observed mainly at the dentin/adhesive interface. The bonding to dentin is obtained by the formation of a hybrid layer; however, the longevity of the hybrid layer has still been widely questioned as a consequence of hydrolytic degradation of the adhesive interface over time [1-3].

Among the various factors that are related to the degradation of the hybrid layer, two factors are highlighted: the hydrolytic degradation over time of the polymer present in the hybrid or adhesive layers [4], and a poorly infiltrated hybrid layer with unprotect collagen fibers $[1,4]$. This unprotected collagen can hydrolyze by host-derived matrix metalloproteinase (MMP) enzymes [5-7]. Therefore, new strategies are being exhaustively studied with the purpose of increasing the durability of the dentin/bond interface, one of which is the inhibition of MMP's proteolytic activity within the unprotected collagen fibers [5-8].

MMPs require $\mathrm{Zn}^{2+}$ ions to maintain their proper tertiary structure and functional active sites [9]. On the other hand, $\mathrm{Zn}$ can be used to protect collagen from MMPs activity [10-12]. Previous studies [5-8] observed the durability of the resin/dentin interface when $\mathrm{Zn}$ was added to commercial dental adhesives. $\mathrm{Zn}$ can promote subtle conformational in collagenase cleavage sites in collagen molecules that protect collagen from MMP's activity [5,7]. The incorporation of $\mathrm{Zn}$ in commercial adhesives has also resulted in the formation of apatite crystallites on the collagen fibrils, favoring dentin mineralization [5], reduce MMPs-mediated collagen degradation [5,12], may inhibit dentin demineralization [13], and may promote enamel remineralization [14].

However, any change in the chemical composition of adhesive systems involves potential mechanical and physicochemical failures and biohazards. Therefore, the insertion of $\mathrm{Zn}$ in adhesive systems as an alternative to preserve the longevity of the restoration, although having promising results, requires further reviews, due to the possibility of changing adhesive systems' biological, physico-chemical and mechanical properties, and, consequently, their clinical performance.

The aim of this study was to evaluate a 6 month resin/dentin bond's durability of $\mathrm{Zn}$-doped etch-and-rinse model dentin adhesives. Mechanical properties (diametral tensile strength, flexural strength, flexural modulus, resilience modulus, and compressive strength) and physicochemical properties (polymerization shrinkage, contact angle, water sorption, and water solubility) were also tested. In vitro cytotoxicity of these adhesives was evaluated on human dental pulp fibroblasts.

This study tested three null hypotheses: (1) the model dentin adhesives tested can achieve similar bond durability to dentin; (2) the storage period does not affect the bonding effectiveness of model dentin adhesives; and (3) the model dentin adhesives tested can achieve similar results for mechanical and physicochemical properties and cytotoxicity.

\section{Material and methods}

\subsection{Model dentin adhesives preparation}

A model simplified etch-and-rinse adhesive was formulated through intensive mixing of bisphenol-A diglycidyl ether dimethacrylate (Bis-GMA) and 2-hydroxyethyl methacrylate (HEMA), with a mass ratio of 45:55 (HEMA:BisGMA). The photoinitiators used were $0.5 \mathrm{~mol} \%$ of camphorquinone as a hydrophobic photosensitizer and $0.5 \mathrm{~mol} \%$ of 2-(dimethylamino) ethyl methacrylate (DMAEMA) as a hydrophilic co-initiator. Model dentin adhesives were prepared in a brown glass vial in the absence of visible light. All materials were obtained from Aldrich Chemical Co. (Milwaukee, WI, USA) [15].

Zinc methacrylate (Sigma Aldrich) and ZnO nanoparticles (Sigma Aldrich) were added to the control model dentin adhesive at 1, 2, 5, and $10 \mathrm{wt}$. \% concentrations. The $\mathrm{Zn}$-doped model dentin adhesives were shaken using a tube agitator in the dark for $10 \mathrm{~min}$ at $2000 \mathrm{rpm}$.

\subsection{Degree of conversion (pilot study)}

In order to obtain a maximal concentration that did not alter the conversion degree of the $\mathrm{Zn}$-doped model dentin adhesives, the degree of conversion of polymerized $\mathrm{Zn}$ doped adhesives was compared to the control model dentin adhesive. The degree of conversion was determined using Raman spectroscopy. Spectra were collected using a MicroRaman spectrometer (model 2000, Renishaw Engineering, Wotton-under-Edge, UK) with an Argon laser as an excitation source. To determine the degree of conversion, spectra of a droplet of uncured adhesives and polymerized adhesives were acquired over a spectral range of $700-1800 \mathrm{~cm}^{-1}$. The change of the band height ratios of the aliphatic carbon-carbon double bond (peak at $1640 \mathrm{~cm}^{-1}$ ) and the aromatic $\mathrm{C}=\mathrm{C}$ (peak at $1610 \mathrm{~cm}^{-1}$ ) (phenyl) in both the cured and uncured states was monitored. The degree of conversion was calculated using the following formula based on the decrease 
Table 1 - Results of Tukey's test for degree of conversion (\%) of the adhesive polymers.

\begin{tabular}{lc} 
Experimental adhesives & $\begin{array}{c}\text { Degree of } \\
\text { conversion \% } \\
(\text { SD })\end{array}$ \\
\hline Control dentin adhesive & $87.25(3.65) \mathrm{a}$ \\
Zinc methacrylate $1 \%$ & $86.90(3.18) \mathrm{a}$ \\
Zinc oxide nanoparticles 1\% & $86.66(3.20) \mathrm{a}$ \\
Zinc oxide nanoparticles $\%$ & $81.08(1.33) \mathrm{b}$ \\
Zinc oxide nanoparticles 5\% & $80.27(2.19) \mathrm{b}$ \\
Zinc methacrylate $2 \%$ & $79.27(1.72) \mathrm{b}$ \\
Zinc oxide nanoparticles 10\% & $79.12(1.79) \mathrm{b}$ \\
Zinc methacrylate 5\% & $77.71(1.65) \mathrm{b}$ \\
Zinc oxide nanoparticles 10\% & $77.62(1.42) \mathrm{b}$ \\
\hline Values are mean \pm SD. & \\
Letters show significant differences between the groups.
\end{tabular}

in the intensity band ratios before and after light curing (Eq. (1)):

$D C(\%)=\left(1-\left(\frac{R_{\text {cured }}}{R_{\text {uncured }}}\right)\right) \times 100$

All experiments were carried out in triplicate and the results were averaged. The results were analyzed statistically using one-way analysis of variance (ANOVA) and Tukey's test (5\%).

The degree of conversion for all adhesives was in the range of $87-77 \%$. Zn-Doped adhesives at 2, 5, and 10 wt.\% concentrations showed a significantly lower degree of conversion (degree of freedom $=9, F=124, p=0.000$ ) as compared to the control adhesive. Table 1 shows Tukey's results of the degree of conversion of the adhesive polymers.

Based on the results of the pilot study (Table 1), it was used three formulations of dentin adhesives: (1) control dentin adhesive (Control adhesive); (2) Zn-doped dentin adhesive with 1 wt.\% Zinc methacrylate (Zn-Mt adhesive); and (3) Zndoped dentin adhesive with $1 \mathrm{wt} . \% \mathrm{ZnO}$ nanoparticles ( $\mathrm{ZnOn}$ adhesive).

The three tested model dentin adhesives (Control adhesive, $\mathrm{Zn}$-Mt adhesive, and $\mathrm{ZnOn}$ adhesive) were evaluated in vitro for longitudinal microtensile bond strength (mTBS), diametral tensile strength, flexural strength, flexural modulus, resilience modulus, compressive strength, water sorption, water solubility, polymerization shrinkage, contact angle, and cytotoxicity.

\subsection{Microtensile bond strength (mTBS)}

Sixty extracted healthy human molars were used. The Research Ethics Committee of the São Jose dos Campos School of Dentistry - UNESP approved this study. A flat dentin surface was exposed after grinding the occlusal enamel using abrasive water papers (450-grit) under water cooling (Politriz, DP-10, Panambra, São Paulo, SP, Brazil). The smear layers of the dentin surfaces were standardized with 600-grit silicon carbide paper for $30 \mathrm{~s}$ under water cooling.

Before the restorative procedures, a solvent of $30 \mathrm{wt} . \%$ (99\% ethanol, Sigma Aldrich) was mixed into to the model dentin adhesives, using a shaker tube in the dark for $3 \mathrm{~min}$ at $2000 \mathrm{rpm}$.
The dentin surfaces were etched for $15 \mathrm{~s}$ with a $37 \%$ phosphoric acid gel (CondacAC 37\%, FGM Prod. Odont., Ltda, Joinville, SC, Brazil), rinsed, and the excess moisture was removed with absorbent paper. Two layers of model dentin adhesives were applied on the surface actively for $20 \mathrm{~s}$ and gently air dried for $10 \mathrm{~s}$. Adhesives were light activated for $20 \mathrm{~s}$ with an LED light unit (Demi LED Light Curing System) with a power density of $1000 \mathrm{~mW} / \mathrm{cm}^{2}$.

Composite build-ups (Filtek Z350, 3 M ESPE, St. Paul, MN, USA) were placed on the bonded surfaces ( $4 \mathrm{~mm}$ high, in 2 increments). Each $2 \mathrm{~mm}$ portion was light activated for $40 \mathrm{~s}$. The bonded teeth were stored in distilled water at $37^{\circ} \mathrm{C}$ for $24 \mathrm{~h}$.

To obtain six sticks per tooth, the teeth were cut in both " $x$ " and " $y$ " directions across the bonded interface into parallel sections measuring approximately $1 \mathrm{~mm}$, using a diamond disk (Labcut 1010, Extec Technologies Inc., Enfield, CT, USA) at low speed and under water cooling.

Half of the total sticks from each group were immediately tested for $\mu$ TBS and the other half were stored in distilled water at $37^{\circ} \mathrm{C}$ for 6 months before testing. The water was changed weekly.

The sticks were attached to a microtensile device in a universal testing machine (DL-1000, EMIC, São José dos Pinhais, PR, Brazil), with a $10 \mathrm{~kg}$ load cell, at a cross-head speed of $0.5 \mathrm{~mm} / \mathrm{min}$, according to ISO 11405 Standard. The bond strength data were expressed in megapascals (MPa).

The failure modes were analyzed with a $20 \times$ stereomicroscope (Stemi 2000 - Karl Zeiss, Göttingen, Germany) and were classified as adhesive, mixed, or cohesive in dentin or composite. Only the adhesive and mixed failures were included in the statistical analysis. The mean value for the sticks originating from each tooth was calculated and used for the statistical analysis. Data were analyzed by two-way ANOVA (adhesive and storage time) followed by Tukey test ( $\alpha 5 \%)$.

Two teeth from each group were used in the Scanning electron microscopy (SEM) analysis according to Marimoto et al. [16]. After bonding and restorative procedures, the teeth were sectioned perpendicularly to the bonding interface and were stored in distilled water at $37^{\circ} \mathrm{C}$ for $24 \mathrm{~h}$ or 6 months. Then, the sections were polished with 2000 and 4000 mesh sheets. Phosphoric acid etchant was applied for $5 \mathrm{~s}$ and rinsed off with water for $10 \mathrm{~s}$. Specimens were dehydrated, sputter-coated with gold-palladium, and the bonding interfaces were examined using SEM.

\subsection{Flexural strength, modulus of elasticity and resilience modulus}

Ten specimens of each group were prepared for the test. Unpolymerized model dentin adhesive was placed on rectangular silicon molds $(25 \mathrm{~mm}$ long $\times 2 \mathrm{~mm}$ wide $\times 2 \mathrm{~mm}$ high; ISO 4049), which were covered with a Mylar strip and a glass slide. Specimens were light polymerized on the top for $20 \mathrm{~s}$ (Demi LED Light Curing System) at 3 different positions (right, middle, and left). Additional light-activation was made for $20 \mathrm{~s}$ on the bottom surface. Specimens were stored for $24 \mathrm{~h}$ in distilled water at $37^{\circ} \mathrm{C}$ and subjected to a three-point bending test using a universal testing machine (DL-1000, EMIC, São José dos Pinhais, PR, Brazil) [17]. 
After the specimens had been finished with 1000-grit silicon carbide paper, their final dimensions were measured. Specimens were individually stored in deionized water at $37^{\circ} \mathrm{C}$ for $24 \mathrm{~h}$ prior to testing. The flexural properties were evaluated by a three-point bending test using the same universal testing machine at a crosshead speed of $1.0 \mathrm{~mm} / \mathrm{min}$. Flexural strength was obtained by measuring the load at fracture, and the modulus of elasticity was calculated from the recorded load-deflection curves $[17,18]$.

The coefficients of variation for the resilience modulus (in $\mathrm{MPa}$ ) were calculated from the data of the flexural strength and modulus of elasticity using the formula described in Eq. (2).

$\mathrm{RM}=\frac{(\mathrm{FS})^{2}}{2 x(\mathrm{ME})}$

FS is the flexural strength (in MPa), and ME is the modulus of elasticity (in $\mathrm{MPa}$ ).

Data collected of flexural strength (in $\mathrm{MPa}$ ), modulus of elasticity (in $\mathrm{GPa}$ ), and resilience modulus (in $\mathrm{MPa}$ ) were statistically analyzed using one-way ANOVA and Tukey's test $(p<0.05)$.

\subsection{Diametral tensile strength}

For the diametral tensile strength test, 10 specimens of each group were prepared. Three increments (approximately $2 \mathrm{~mm}$ each) of unpolymerized model dentin adhesive was placed in a cylindrical silicon mold $(4.0 \mathrm{~mm}$ in diameter $\times 6.0 \mathrm{~mm}$ in height), and each increment was light polymerized for $20 \mathrm{~s}$ (Demi LED Light Curing System). The third increment was recovered with a Mylar strip and a glass slide. Additional lightactivation for $20 \mathrm{~s}$ was done on the lateral portions of the cylinder. Specimens were then stored in distilled water at $37^{\circ} \mathrm{C}$ for $24 \mathrm{~h}$.

The specimens were tested under a compressive load in the universal testing machine (DL-1000, EMIC, São José dos Pinhais, PR, Brazil) at a crosshead speed of $1.0 \mathrm{~mm} / \mathrm{min}$. Load was applied vertically on the lateral portion of the cylinder. Fracture load (F) (in N), was recorded and the diametral tensile strength (in MPa) was calculated (Eq. (3)).

$\mathrm{DTS}=\frac{2 \mathrm{~F}}{\pi \times d \times l}$

Since $d$ is the diameter $(4 \mathrm{~mm}), h$ is the height $(6 \mathrm{~mm})$, and $\pi$ is 3.1416 .

\subsection{Compressive strength}

Ten specimens of each model dentin adhesive were prepared using a silicon mold ( $4.0 \mathrm{~mm}$ in diameter $\times 8.0 \mathrm{~mm}$ in height). The silicon mold was filled in four approximately $2.0-\mathrm{mm}$ thick increments, and each increment was light-activated for 20 s. After insertion of the last increment, a Mylar strip and a glass slide were placed onto the silicon mold and light curing was done. Additional light-activation for $20 \mathrm{~s}$ was done on the lateral portions of the cylinder. Specimens were then stored in distilled water at $37^{\circ} \mathrm{C}$ for $24 \mathrm{~h}$.
The specimens were tested under a compressive load in compressive strength in the universal testing machine (DL1000, EMIC) with a crosshead speed of $1 \mathrm{~mm} / \mathrm{min}$. The data were obtained in $\mathrm{N}$ and converted to $\mathrm{MPa}$ using the formula shown in Eq. (4).

$\mathrm{CS}=\frac{\mathrm{F}}{\mathrm{A}}$

Since CS is the compressive strength (MPa), $F$ is the supported maximum load $(\mathrm{N})$, and $\mathrm{A}$ is the cross-sectional area of the specimen $\left(\mathrm{mm}^{2}\right)$.

Data were tabulated and analyzed statistically using oneway ANOVA and the Tukey test for pairwise comparisons. Significance level was set at 5\%.

\subsection{Water sorption and water solubility}

Ten disk-shaped specimens of each model dentin adhesive were fabricated using a silicon mold $(6.0 \mathrm{~mm}$ in diameter $\times 2.0 \mathrm{~mm}$ in height) (ISO 4049.2000). One increment of unpolymerized model dentin adhesive was placed in the silicon mold, and a Mylar strip and a glass slide were placed onto the silicon mold and light-polymerized for $20 \mathrm{~s}$. Additional light-activation for $20 \mathrm{~s}$ was done on the bottom of the specimen. Specimens were stored in a desiccator containing freshly dried silica gel $[15,18]$. After $24 \mathrm{~h}$, the specimens were weighed with a precision balance of $0.0001 \mathrm{mg}$ (model Ohaus Adventurer, Barueri, SP, Brazil). This cycle was repeated until a constant mass $\left(m_{i}\right)$ was obtained. The specimens were immersed in $1 \mathrm{ml}$ of distilled water at $37^{\circ} \mathrm{C}$. Every $24 \mathrm{~h}$, specimens were removed, blotted dry, re-weighed $\left(m_{\mathrm{s}}\right)$ and returned to the water. After 28 days, specimens were again dried inside a desiccator and weighed daily until constant mass was obtained $\left(m_{\mathrm{d}}\right)[15,18]$. Water sorption (WS) and water solubility (WL) were calculated using the formula (ISO 2000) shown in Eqs. (5) and (6) respectively.

$$
\begin{aligned}
& \mathrm{WS}(\%)=\left(\frac{m_{\mathrm{s}}-m_{\mathrm{i}}}{m_{\mathrm{i}}}\right) \times 100 \\
& \mathrm{WL}(\%)=\left(\frac{m_{\mathrm{i}}-m_{\mathrm{d}}}{m_{\mathrm{i}}}\right) \times 100
\end{aligned}
$$

The data are given in percentage of total loss of weight (water solubility) or gain of weight (water sorption) [17,19].

Data were tabulated and analyzed statistically using oneway ANOVA and the Tukey test for pairwise comparisons. Significance level was set at $5 \%$.

\subsection{Contact angle}

The ADSA-CD (Axisymmetric Drop Shape Analysis Contact Diameter) technique was used to measure the contact angle. For each experimental adhesive, five drops (volume of approximately $0.8 \mathrm{ml}$ ) of distilled water were deposited using a goniometer on five slices of flat surface of polymerized model dentin adhesives over a glass slide. The contact angle measurement was made by an automated contact angle measurement instrument (Rame-Hart, Inc., 100-00, Contact Angle Goniometers, Mountain Lakes, USA). The image of the drop 
Table 2 - Mean (SD) of flexural strength, modulus of elasticity, resilience modulus, diametral tensile strength, compressive strength, water sorption, water solubility, polymerization volume shrinkage, and contact angle values of model dentin adhesives.

\begin{tabular}{|c|c|c|c|c|c|c|c|c|c|}
\hline & $\begin{array}{l}\text { Flexural } \\
\text { strength } \\
(\mathrm{MPa})\end{array}$ & $\begin{array}{l}\text { Modulus of } \\
\text { elasticity } \\
\text { (GPa) }\end{array}$ & $\begin{array}{l}\text { Resilience } \\
\text { modulus } \\
(\mathrm{MPa})\end{array}$ & $\begin{array}{l}\text { Diametral } \\
\text { tensile } \\
\text { strength } \\
(\mathrm{MPa})\end{array}$ & $\begin{array}{l}\text { Compressive } \\
\text { strength } \\
\text { (MPa) }\end{array}$ & $\begin{array}{l}\% \text { Water } \\
\text { sorption }\end{array}$ & $\begin{array}{l}\% \text { Water } \\
\text { solubility }\end{array}$ & $\begin{array}{l}\text { \%Polymerization } \\
\text { volume } \\
\text { shrinkage }\end{array}$ & $\begin{array}{l}\text { Contact } \\
\text { angle }\left(^{\circ}\right)\end{array}$ \\
\hline Control & $188.5(28.8) a$ & $2.2(0.5) a$ & $8.1(1.8) a$ & 96.3 (17.1)a & 332.7 (82.5)a & $7.73(0.47) a$ & $-4.27(0.24) \mathrm{a}$ & $12.14(0.27) a$ & $61.91(5.45) \mathrm{a}$ \\
\hline $\mathrm{ZnOn}$ & $198.2(28.2) \mathrm{a}$ & $2.5(0.4) a$ & $7.7(1.0) \mathrm{a}$ & $87.4(20.8) a$ & 334.9 (74.5)a & $7.56(0.35) a$ & $-4.29(0.34) a$ & $10.83(0.53) \mathrm{b}$ & 55.68 (7.18)a \\
\hline Zn-Mt & $173.1(25.2) \mathrm{a}$ & $2.5(0.4) a$ & $5.9(1.0) b$ & $92.7(33.8) a$ & $316.1(58.2) \mathrm{a}$ & $7.86(0.51) a$ & $-4.21(0.29) a$ & $10.96(0.46) \mathrm{b}$ & $55.28(8.65) \mathrm{a}$ \\
\hline $\begin{array}{l}\text { Values a } \\
\text { Letters s } \\
\text { \%Water }\end{array}$ & $\begin{array}{l}\text { nean } \pm S D \\
N \text { significa } \\
\text { ubility of } n\end{array}$ & ive value & due to in & s. & & & & & \\
\hline
\end{tabular}

was taped for 5 min using a video camera and captured on a computer that provided the contact angle values. The data are given in angles.

Data were tabulated and analyzed statistically using oneway ANOVA and the Tukey test for pairwise comparisons. Significance level was set at $5 \%$.

\subsection{Polymerization volume shrinkage}

The polymerization volume shrinkage of the model dentin adhesives was measured with the instrument Accurate volumetric shrinkage (Acuvol ${ }^{\mathrm{TM}}$, Bisco Inc., IL, USA). Five drops (total volume of $2 \mu \mathrm{l}$ ) of each adhesive were placed with a micropipette on a platform of the equipment. After $15 \mathrm{~s}$, a video captured images (10 reads) of the drop. This allowed for comparison of the volumes of the adhesives before and after light curing for $20 \mathrm{~s}$, and also allowed for the calculation of the percentage of volume change after the light cure. The polymerization volume shrinkages are given in percentage of total reduction of the volume of the adhesive by the computer coupled to the equipment.

Data were tabulated and analyzed statistically using oneway ANOVA and the Tukey test for pairwise comparisons. Significance level was set at $5 \%$.

\subsection{Cytotoxicity}

\subsubsection{Cell culture}

Fibroblasts (FP7 cell line) derived from a human third molar germ were cultured in DMEM, supplemented by $10 \%$ fetal bovine serum (Gibco Laboratories, Grand Island, NY, USA) and $1 \%$ antimycotic-antibiotic solution (10,000 units of penicillin, $10 \mathrm{mg}$ of streptomycin, and $25 \mu \mathrm{g}$ of amphotericin $\mathrm{B} / \mathrm{ml}$ in $0.9 \%$ sodium chloride; Sigma Aldrich). The cells were kept in an incubator at $37^{\circ} \mathrm{C}$ and a humidified $5 \% \mathrm{CO}_{2}$ atmosphere. Cultures were supplied with fresh medium every other day [20].

\subsubsection{Cell treatment}

After cell culture, cells were plated in 96 well plates at a density of 3.000 cells per well. All plates were incubated for $24 \mathrm{~h}$ in $37^{\circ} \mathrm{C}$ incubator $\left(5 \% \mathrm{CO}_{2}\right)$. To obtain the conditioned medium, test tubes containing $0.4 \mathrm{~g}$ of adhesive were filled with $1 \mathrm{ml}$ of fresh DMEM to each group. The medium were placed in contact with the uncured adhesives and agitated in the
Vortex for $1 \mathrm{~min}$ for homogenization [20]. After $24 \mathrm{~h}$ of plating, the medium was removed and the cell cultures were exposed to $100 \mu \mathrm{l}$ of serial dilutions ( $10 \%, 1 \%, 0.1 \%, 0.01 \%), 100 \mu \mathrm{l}$ of culture medium with cells (positive control), and $100 \mu$ l culture medium without cells (blank-negative control). The plates were incubated for $24 \mathrm{~h}, 48 \mathrm{~h}$, and $72 \mathrm{~h}$ in $37^{\circ} \mathrm{C}$ incubator $(5 \%$ of $\mathrm{CO}_{2}$ ).

\subsubsection{Sulforhodamine B (SRB) colorimetric assay}

Cellular proteins are marked by adding the solution of protein dye sulforhodamine B (SRB) $0.4 \%$ acetic acid (1\%) and incubated for $30 \mathrm{~min}$ at room temperature. The SRB was removed and the plates were washed five times with $1 \%$ acetic acid before air-drying. Bound SRB was resolubilized with unbuffered Tris-base $10 \mathrm{mM}$ solution [20,21].

Absorbance was read at a wavelength of $570 \mathrm{~nm}$ as described previously $[20,21]$. The viability percentage of the cell population of each dish was obtained and normalized for negative control statistically analysis. The absorbance found for the positive control (cells grown only in DMEM media) corresponds to a value of $100 \%$ survival.

The data were compared by Kruskal-Wallis $(p<0.05)$ and with Dunn's multiple comparison test (5\%).

\section{Results}

Table 2 shows the flexural strength, modulus of elasticity, resilience modulus, diametral tensile strength, compressive strength, \%water sorption, \%water solubility, \%polymerization volume shrinkage and contact angle mean values for the Control, $\mathrm{Zn}-\mathrm{Mt}$, and $\mathrm{ZnOn}$ adhesives. The incorporation of $\mathrm{Zn}-\mathrm{Mt}$ or $\mathrm{ZnOn}$ at $1 \%$ showed no statistical difference in flexural strength, modulus of elasticity, diametral tensile strength, compressive strength, \%water sorption, \%water solubility, and contact angle when compared with the control adhesive $(p>0.05)$. Incorporation of $\mathrm{Zn}-\mathrm{Mt}$ or $\mathrm{ZnOn} 1 \mathrm{wt} . \%$ significantly decreased the \%polymerization volume shrinkage when compared with the control adhesive $(F=18.7 ; p<0.00)$. Incorporation of $\mathrm{Zn}-\mathrm{Mt}$ at $1 \mathrm{wt} . \%$ significantly decreased the resilience modulus when compared with the $\mathrm{ZnOn}$ and Control adhesives $(F=7.72 ; p<0.00)$.

Bond strength was affected by adhesives $(F=15.66$; $p<0.000)$ and storage time $(F=31.78 ; p<0.000)$. Interactions were also significant $(F=6.31 ; p<0.003)$. 
Table 3 - Mean \pm standard deviation (in MPa) obtained for different model dentin adhesives for $24 \mathrm{~h}$ and 6 months.

\begin{tabular}{lrr} 
Model dentin adhesives & Storage time & Mean (SD) \\
\hline ZnOn & $24 \mathrm{~h}$ & $28.65(6.05) \mathrm{a}$ \\
$\mathrm{ZnOn}$ & 6 months & $27.75(4.02) \mathrm{a}$ \\
$\mathrm{Zn}-\mathrm{Mt}$ & $24 \mathrm{~h}$ & $26.36(6.05) \mathrm{a}$ \\
Control & $24 \mathrm{~h}$ & $24.81(8.02) \mathrm{a}$ \\
Zn-Mt & 6 months & $14.22(3.59) \mathrm{b}$ \\
Control & 6 months & $13.79(4.27) \mathrm{b}$ \\
\hline
\end{tabular}

Values are mean $\pm \mathrm{SD}$

Letters show significant differences between the groups.

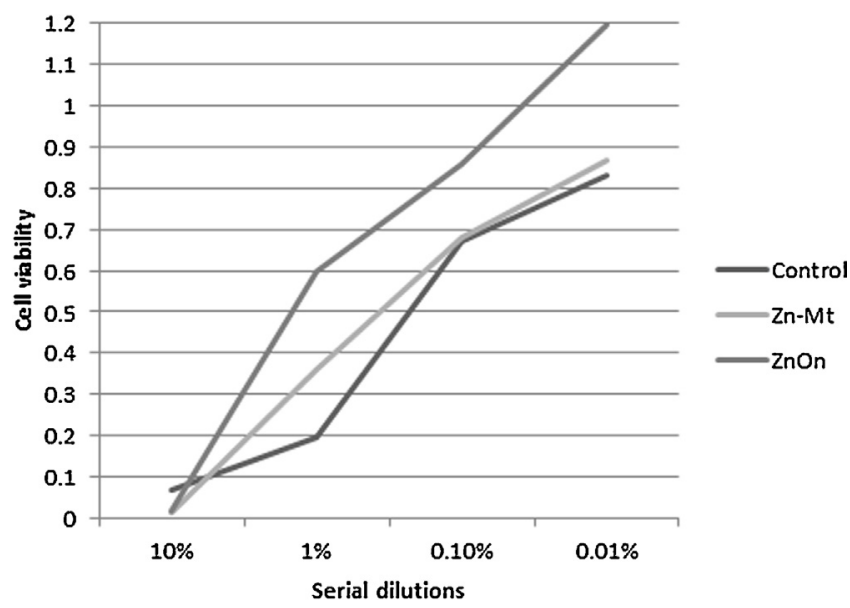

Graph 1 - Viability curves, in percentage, of FP7 cells in serial dilutions of adhesives.

\begin{tabular}{|c|c|}
\hline Model dentin adhesives & Mean (SD) \\
\hline $\mathrm{ZnOn}$ & $59.9(20.8) \mathrm{a}$ \\
\hline Zn-Mt & $36.2(11.4) \mathrm{b}$ \\
\hline Control & $19.3(4.1) \mathrm{b}$ \\
\hline
\end{tabular}

Mean bond strength values obtained for each group in different storage times are displayed in Table 3. All model dentin adhesives showed a similar value at $24 \mathrm{~h}$. After 6 months of water storage, bond strength values did not decrease for the $\mathrm{ZnOn}$ adhesive, whilst the Control and $\mathrm{Zn}-\mathrm{MT}$ adhesives showed a significantly lower bonding efficacy.

For the fracture type, there was observed an increase in the percentage of adhesive failures in the time interval of 6 months, being more pronounced for the $\mathrm{Zn}-\mathrm{Mt}$ (97\% adhesive failure) and Control ( $95 \%$ adhesive failure) adhesives.

Graph 1 shows the viability curves, in percentage, of FP7 cells in serial dilutions of the adhesives tested.

For cytotoxicity, there were statistically significant differences between the adhesives tested ( $F=17.1 ; p<0.000)$. The ZnOn adhesive presents significantly higher cell viability when compared to the Zn-MT and Control adhesives for $1 \%$ medium dilution (Table 4 ).
Figs. 1-3 illustrate the dentin/resin interface formed by, respectively, Control adhesive, $\mathrm{ZnOn}$ adhesive, and $\mathrm{Zn}-\mathrm{Mt}$ adhesive, been $\mathrm{A}(24 \mathrm{~h})$ and $\mathrm{B}$ ( 6 months) water storage.

Figs. 1-3 illustrate the SEM micrographs of the bonded interface in dentin with, respectively, Control adhesive, $\mathrm{ZnOn}$ adhesive and $\mathrm{Zn}-\mathrm{Mt}$ adhesive, been A ( $24 \mathrm{~h}$ ) and B (6 months) water storage. Adhesives generally showed a well-developed resin impregnated zone (hybrid layer) for $24 \mathrm{~h}$ of water storage (Figs. 1A, 2A and 3A). The Control Adhesive and Zn-Mt adhesive showed, respectively, the presence of cracks and gaps in the interface for 6 months of water storage (Figs. 1B and 3B). Fig. $2 \mathrm{~B}$ shows a bonded interface, created using the $\mathrm{ZnOn}$ adhesive, without cracks after 6 months water storage.

\section{Discussion}

From the clinical perspective, the degree of conversion is one of the most important physicochemical properties of dental restorative materials. Therefore, the first step of this research (pilot study) was to evaluate the degree of conversion of the adhesives when $\mathrm{ZnOn}$ and $\mathrm{Zn}$-Mt were added in different concentrations. Incorporation of $\mathrm{ZnOn}$ or $\mathrm{Zn}-\mathrm{Mt}$ at 2, 5 , and $10 \mathrm{wt}$ \% into the adhesive could significantly sacrifice the degree of conversion compared to the control adhesive (Table 1). The present findings demonstrated that the incorporation of $\mathrm{ZnOn}$ and $\mathrm{Zn}-\mathrm{Mt}$ at these concentrations into a model etch-and-rinse single-bottle adhesive did cause negative effect on the degree of conversion. It could be suggested that $\mathrm{ZnOn}$ and $\mathrm{Zn}-\mathrm{Mt}$ at concentrations of 2, 5, and $10 \mathrm{wt} . \%$ may: (1) prevent the conversion of monomers into polymers, decreasing the crosslink densities of these adhesives; (2) promote the formation of structural defects in the cross-linked polymer; and (3) decrease the penetration of the light beam of a light system in the adhesives due the high opacity of the $\mathrm{ZnOn}$ and high yellowness of the $\mathrm{Zn}-\mathrm{Mt}$, modifying the transparency of the whole adhesive. From this pilot study, it was determined that the concentration of $1 \mathrm{wt} . \%$ of $\mathrm{ZnOn}$ and $\mathrm{Zn}$ Mt was to be added in the model dental adhesive with the intention of preventing alteration of the physical and mechanical properties in it.

The main objective of any dental bonding system is promoting a strong and durable bond between the dental material and the tooth tissue, and this bond durability is usually tested with microtensile bond strength tests. Incorporation of $\mathrm{ZnOn}$ $1 \mathrm{wt} . \%$ in model dental adhesives led to higher bond strength values when compared to the $\mathrm{Zn}-\mathrm{Mt}$ and Control adhesives, rejecting the first hypothesis. The $\mathrm{Zn}-\mathrm{Mt}$ and Control adhesives showed a decrease of bond strength after 6 months of water storage, so the second hypothesis was also rejected.

When model dentin adhesive was $\mathrm{Zn}$-doped with $\mathrm{ZnOn}$ or $\mathrm{Zn}-\mathrm{Mt}$ (1 wt.\%), the $24 \mathrm{~h}$ bond strength was not affected. Also, it can be observed that a well-defined hybrid layer was created with all adhesives tested (Figs. 1A, 2A and 3A). However, improvements in the resin/dentin bonds' durability have been shown when model dentin adhesive was doped with $\mathrm{ZnOn}$. An increase in research involving $\mathrm{ZnOn}$ in medicine and dentistry as biomaterials can be observed [8,22-26]. Zinc oxide is characterized as a fine, amorphous white powder and amphoteric in nature [27], and is found naturally in a mineral called 

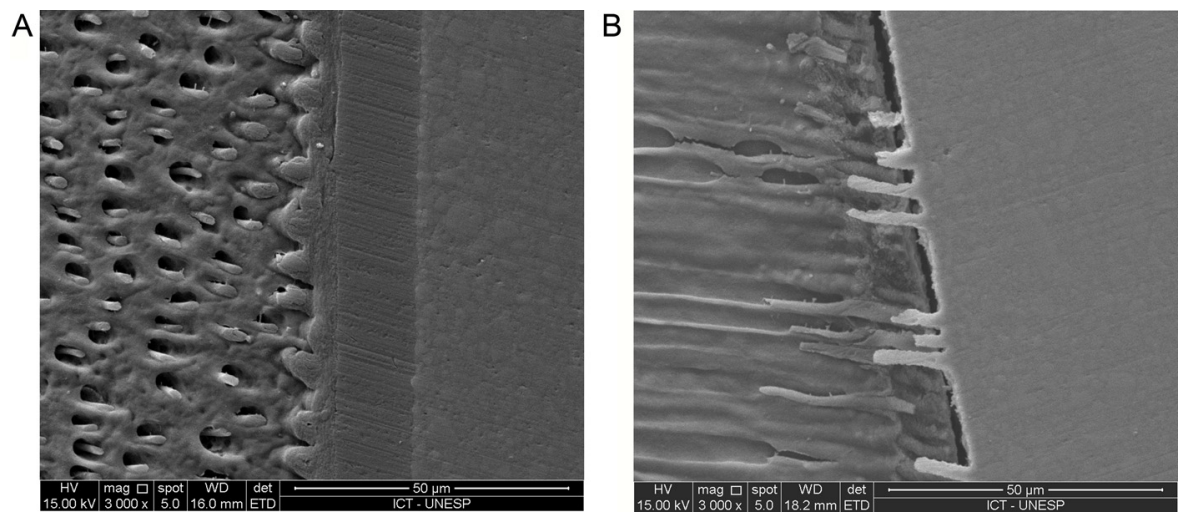

Fig. 1 - SEM analysis. (A) Well-defined hybrid layer created with the Control adhesive, and the presence of resin tags can be observed for $24 \mathrm{~h}$ of water storage $(3000 \mathrm{x})$; (B) presence of cracks in the interface can be observed for 6 months of water storage $(3000 x)$.
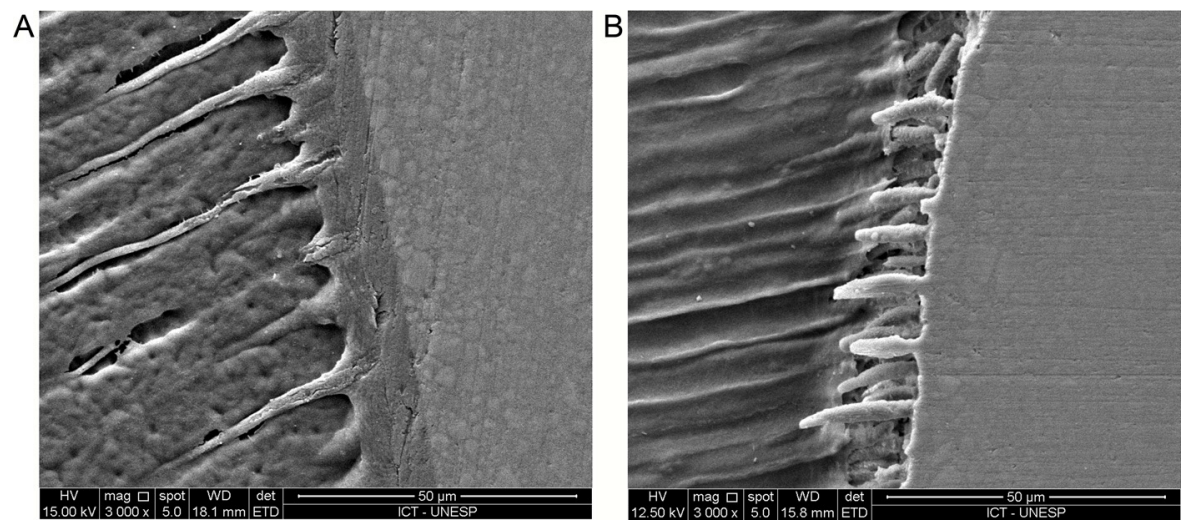

Fig. 2 - SEM analysis. (A) ZnOn adhesive promotes formation of a hybrid layer similar to Control adhesive for $24 \mathrm{~h}$ water storage $(3000 \mathrm{x})$; (B) for six months there were no cracks in the bonded interface $(3000 \mathrm{x})$.

zincita. Being highly transparent to visible light, zinc oxide is in the class of transparent conductive oxides, with their surfaces polar highly stable. It is nearly insoluble in water and alcohol, but soluble (degradable) in most acids, and is fully photo stable $[8,27,28]$.

MMPs have a zinc-binding catalytic domain, and their activity is completely dependent on the $\mathrm{Zn}^{2+}$ ion [10]. On other hand, $\mathrm{Zn}^{2+}$ is a potent inhibitor of MMP-2 and MMP-9 proteolytic activities $[10,29]$. MMP-2 and MMP-9 are active in the degradation of unprotected collagen demineralization and not infiltrated by the adhesive during the formation of the hybrid layer [30,31]. There are several evidences [32-34] indicating that these MMPs play an important role in the longitudinal degradation of the hybrid layer, therefore, one possibility to
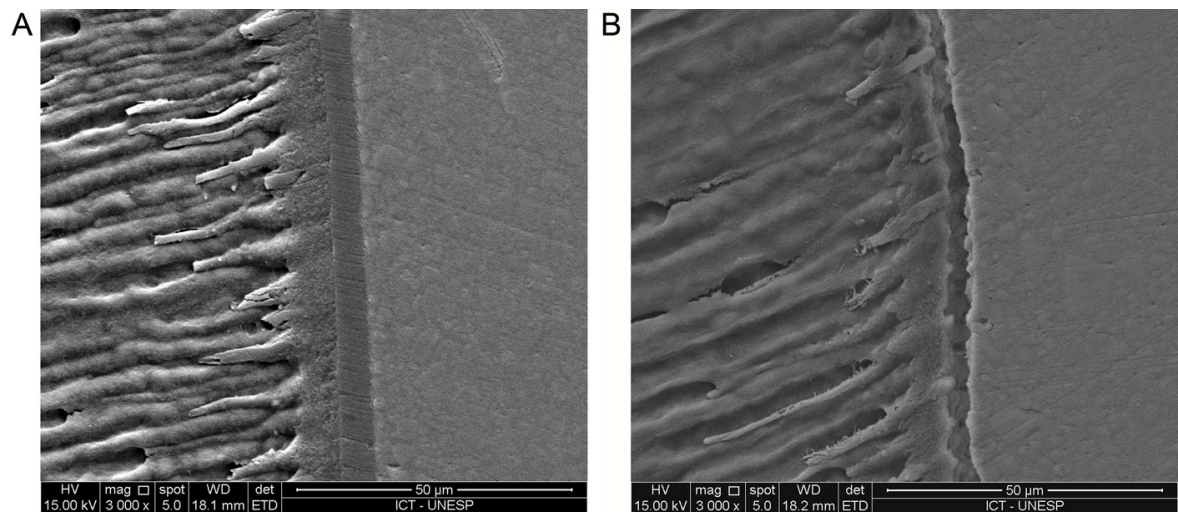

Fig. 3 - SEM analysis. (A) It was observed that $\mathrm{Zn}$-Mt adhesive promotes a formation of an adhesive interface similar to Control adhesive for $24 \mathrm{~h}$ water storage $(3000 \mathrm{x})$; (B) for six months, there was the presence of gaps in the adhesive layer $(3000 x)$. 
increase the longevity of composite restorations is the inhibition of these MMPs' proteolytic activities.

Previous studies have related that $\mathrm{ZnOn}$ exerts collagen protection from MMP degradation and can increase longevity of the resin/dentin interface [5-8]. Toledano et al. [5] explain that collagen molecules have four zinc-binding sites, "at the same location as the collagenase cleavage sites. It seems that subtle conformational changes may occur following zincbinding (of collagen) leading to the protection of sensitive cleavage sites of metalloproteinases" [5]. When added to commercial adhesives, ZnOn particles "preferentially remained at the bottom of the hybrid layer in direct contact with the demineralized dentin" [5], and induces dentin remineralization at the bonded interface [24], because ZnOn promotes stimulus "a metabolic effect in hard tissue mineralization" [5], permitting formation of apatite crystallites on the collagen fibrils and remineralization of unprotect collagen $[5,24]$. Also, the model dentin adhesives used in this study are basically a compound of 55\% Bis-GMA and 45\% HEMA. Some studies suggest that HEMA can inhibit the activity of MMP-2 by immobilizing the catalytic sites of MMPs $[5,12,35,36]$, which can improve the protection of the hybrid layer formed by the ZnOn adhesive.

The results of the current study corroborate with the results obtained in previous studies [5-8], because bond stability of the ZnOn model dentin adhesive was observed after 6 months of water storage. However, those studies used $10 \mathrm{wt}$ \% of $\mathrm{ZnOn}$ added to a commercial adhesive. In this study, it was observed that 2, 5, and $10 \mathrm{wt} . \%$ ZnOn decreased the DC of the model dentin adhesive, and only the concentration of $1 \mathrm{wt} . \%$ of ZnOn incorporated to adhesives did not affect the DC. It was observed that, regardless of the concentration tested $(1,2,5$, and $10 \mathrm{wt} . \%)$, there was no dissolution of $\mathrm{ZnOn}$ in the adhesive, making it whitish and cloudy, which can indicate that ZnOn is poorly soluble or insoluble to the model dentin adhesive. Also, it was observed that for all concentrations of $\mathrm{ZnOn}$ tested in this study, there was a precipitation of $\mathrm{ZnO}$ nanoparticles, which can indicate $\mathrm{ZnOn}$ saturation in the dentin model adhesive. Probably the ZnOn concentration in the adhesive used for mechanical, physico-chemical, and biological properties was lower than the $1 \mathrm{wt} . \%$ added, as part of the $\mathrm{ZnOn}$ precipitate remained even after vigorous shaking. Therefore, it would be interesting to calculate the minimum ion concentration required to enable the precipitation of $\mathrm{ZnOn}$ in the adhesive, and, thereafter, observe if the concentration promotes the beneficial results of increased bond stability.

Different from ZnOn, $1 \mathrm{wt}$ \% $\mathrm{Zn}$-Mt added to the model dentin adhesive was not capable of increasing bond stability of the hybrid layer, having a similar 6 months resin/dentin bond result compared to the control adhesive. The $\mathrm{Zn}-\mathrm{Mt}$ has a methacrylate functional group, which can copolymerize with the other methacrylate monomers, such as Bis-GMA and HEMA [37]. Contrasting with results of this study, Henn et al. [37] observed that Zn-Mt can inhibit MMP-2 expression when added to a dental experimental polymer at $1 \%$ concentration, and did not affect the ultimate tensile strength.

However, the participation of $\mathrm{Zn}^{2+}$ released from the Zn-Mt in the dentin when co-polymerized with adhesives has not been established. Maybe this copolymerization can reduce the release of $\mathrm{Zn}^{2+}$, getting caught in the structure of the methacrylate monomer, inactivating its benefits in the bond/interface after 6 months of water storage. Also, in SEM analysis, a gap in the adhesive layer may be observed for the Zn-Mt adhesive in Fig. 3B, after 6 months of water storage, which can indicate a hydrolytic degradation of the polymer of the adhesive layer. The presence of gaps in the hybrid layer for the control group was also observed (Fig. 1B). Maybe copolymerization between $\mathrm{Zn}-\mathrm{Mt}$ and Bis-GMA/HEMA has a poor resistance to hydrolyses due to the low affinity between them, therefore, there is a need to study in depth the chemical reaction that occurs between these monomers.

Water sorption and solubility are important physical properties, because water is always present in the mouth and can produce deleterious effects on the structure and function of the polymer matrix itself [38]. The penetration of the adhesive system into the substrate is influenced by the contact angle, and it can influence wetting capacity and diffusibility of that material into the substrate. Whilst mechanical properties such as flexural strength, modulus of elasticity, diametral tensile strength, and compressive strength of the resin/based bonding systems are strongly important due to the action of the mechanical loading that occurs during masticatory act, they do not seem to be affected by the incorporation of $\mathrm{ZnOn}$. The results of the current study show that the incorporation of $\mathrm{ZnOn}$ or $\mathrm{Zn}-\mathrm{Mt} 1 \mathrm{wt}$ \% into the model dental adhesives did not significantly affect flexural strength, modulus of elasticity, diametral tensile strength, compressive strength, \%water sorption, \%water solubility, and contact angle of the adhesives. However, Zn-Mt at $1 \mathrm{wt}$.\% decreases the resilience modulus of the model dentin adhesive, incorporation of $\mathrm{Zn}-\mathrm{Mt}$ or $\mathrm{ZnOn} 1 \mathrm{wt} . \%$ decreases the \%polymerization volume shrinkage of the model dentin adhesive, and incorporation of $\mathrm{ZnOn}$ at $1 \mathrm{wt}$ \% increases cell viability of the model dentin adhesive. Therefore, the third hypothesis was partially accepted.

Dentin adhesive is similar to a bridge that provides the mechanism of load transfer between the dentin and the composite $[4,39]$. This is important from the clinical perspective, because dental adhesives are viscoelastic materials that should have satisfactory mechanical and physical properties as a successful restorative dental material, due to the composite restoration coming in contact with occlusal stresses and a wet environment [39]. The drop in the mechanical and physical properties of dental adhesives could lead to degradation of the dentin bond, which accelerates degradation or failure of dentin adhesives, which further causes premature failure of the composite restoration $[4,39]$. The mechanical and physical properties of adhesives strongly depend upon the degree of conversion $[4,40]$. The results presented here showed that the experimental adhesives reached a degree of conversion comparable to that of the control adhesive (Table 1). This means that the addition of ZnOn or Zn-MT at $1 \mathrm{wt} . \%$ does not affect the degree of conversion of the adhesive and most of the physical and mechanical properties which are evaluated in the current study.

However, Zn-Mt significantly reduced the resilience modulus of the model dentin adhesive. The resilient modulus is a physical property in which the material is capable of accumulating energy when required or under stress, and should be as high as possible in dentin adhesives. The high resilience modulus of a restorative material is a factor that helps to preserve 
the adhesive bond between the tooth and the restoration [41], as is the ability of the material to deform or flex and being able to dissipate tensions [41,42]. The high resilience modulus also helps to preserve the adhesive bond between the tooth and restoration, as well as support micro distortions of dental substrates $[42,43]$. This physical property helps single body training between the restoration and the tooth structure [40-43]. It could be suggested that, even with a similar degree of conversion compared to other tested adhesives, the incorporation of $\mathrm{Zn}-\mathrm{Mt}$ at $1 \mathrm{wt} . \%$ in the adhesive may have exhibited reduced crosslink densities, which may promote a decrease of resilience modulus.

It is possible that this reduction may have contributed to decrease the bond-interface after 6 months of water storage for this adhesive. Maybe Zn-Mt reduced the adhesive's ability to flex or deform, which, subsequently, can reduce its ability to dissipate possible tensions that may occur in the adhesive interface, and therefore reduce the success of the restoration. Also, an increase in the percentage of adhesive failures was observed after 6 months of water storage, which is in accordance with the low bond strength values obtained for this group and the Control group, which have similar bond strength values.

According to the results of this research, the Control adhesive had higher polymerization shrinkage values when compared to $\mathrm{Zn}$-doped adhesives. Adhesives are fluid resins which have a polymeric matrix with or without inorganic filler particles. Polymerization shrinkage is the total volume that reduces after photocuring, and is affected mainly by the amount of inorganic filler particles present in the adhesive. During polymerization shrinkage, forces developed that are transmitted as tension in the adhesive interface, which is the most sensitive region of the tooth/restoration [44,45]. These tensions may be responsible for the following: adhesive failures (marginal gaps), postoperative sensitivity, microleakage, reduced marginal integrity, recurrent caries, and decrease of restoration longevity $[46,47]$. The incorporation of $\mathrm{Zn}$ in the model dentin adhesive reduced the total concentration of the polymeric matrix, which is responsible for polymerization shrinkage, thus reducing the polymerization shrinkage of $\mathrm{Zn}$-doped adhesives. A promising result, because the reduction of polymerization shrinkage is desirable to achieve better longitudinal results of dental adhesives.

From the cytotoxicity analysis, this study showed that the ZnOn adhesive is less cytotoxic than the Control and $\mathrm{Zn}$ Mt adhesives. Biocompatibility testing by assays measuring cytotoxicity of adhesive systems is a precondition of dental materials designed for application on human tissues. Dental adhesives can release compounds that have biological effects and toxic potencies [21]. Formation of a hybrid layer biologically seals the interface of the tooth/restoration, and, consequently, protects pulpal tissue $[21,48]$. However, it has been reported that uncured components of adhesives may diffuse across the subjacent dentinal tubules and reach the pulpal tissue [21]. The ranking by toxicity of the component commonly used in adhesive systems (described previously) is as follows [49]: Bis-GMA > UDMA > TEGDMA > HEMA (least toxic), after 24 and $72 \mathrm{~h}$ of exposure. The model dentin adhesive is a compound of 55/45 wt.\%, Bis-GMA/HEMA. However, HEMA has a low molecular weight $(130.14 \mathrm{~g} / \mathrm{mol})$ and high solubility, and it may result in a greater diffusion of unpolymerized HEMA through the dentin when compared to Bis-GMA, which has a higher molecular weight $(512.59 \mathrm{~g} / \mathrm{mol})$.

Although zinc is highly cytotoxic when tested in vitro $[29,50]$, several authors have demonstrated that $\mathrm{ZnOn}$ is biocompatible and bioactive, depending on its concentration. Saha et al. [51] observed that the addition of $10 \mathrm{wt} . \%$ or lower ZnOn to bone composites can enhance the proliferation, adhesion, and differentiation of human osteoblasts and mouse fibroblasts. Memarzadeh et al. [23] observed that ZnOn coating/immobilized on a surface of orthopedic and/or dental implants "could lead to improved bone growth and a more biocompatible, osteoconductive, and antimicrobial implant" [23]. Also, Atsou et al. [11] observed that $1.2 \mathrm{wt}$ \% zinc concentration within a noncytotoxic level embedded calcium phosphate (CaP) ceramics has a pharmaceutical effect of promoting bone formation.

In Graph 1, it can be seen that at $10 \%$ dilution of the adhesives into the culture media, cell growth for all adhesives was less than $10 \%$ ( 0.1 cell viability). But at $1 \%$ dilution of adhesives into the culture media, $\mathrm{ZnOn}$ adhesive allowed fibroblast cell growth of over $50 \%$, which indicates low cytotoxicity for this material. This beneficial effect could be due to the release of $\mathrm{Zn}^{2+}$ from the media, which can either protect the fibroblasts of the Bis-GMA and HEMA compounds or may regulate the metabolism of fibroblasts and them to grow, which will have a positive effect on the biological properties of the adhesives.

However, Zn-Mt was not capable of decreasing the cytotoxicity of adhesive compared to the $\mathrm{ZnOn}$ adhesive, having similar results compared to the Control adhesive. As previously described, the methacrylate functional group of $\mathrm{Zn}-\mathrm{Mt}$ can copolymerize with Bis-GMA and HEMA [37], and this copolymerization maybe reduces the release of $\mathrm{Zn}^{2+}$ to the culture media. This decreased release was not sufficient to promote the positive effects on the fibroblasts that were observed for the $\mathrm{ZnOn}$ adhesive.

The success of the dental restorative materials depends on their physical, chemical, mechanical, and biological properties. According to the findings in this study, $\mathrm{Zn}-\mathrm{Mt}$ is not the preferred component to be inserted into a dentin adhesive single-component, due to reduced resilient modulus of the model dentin adhesive and failure to maintain the 6 month resin/dentin bond's durability.

In conclusion, the incorporation of $\mathrm{ZnOn} \mathrm{T} 1 \mathrm{wt} . \%$ in model dentin adhesives did not affect the $24 \mathrm{~h}$ resin-dentin bond strength, and seems to be promising in the possibility of increasing the longevity of restorations, since it demonstrated improvement in the polymerization shrinkage, in the integrity of the bonded-dentin interface after 6 months of water storage, and in reducing the cytotoxicity of the model dentin adhesives. New research should be conducted in order to observe the clinical performance of $\mathrm{ZnOn}$ adhesives.

\section{REFERENCES}

[1] Spencer P, Ye Q, Park J, Misra A, Bohaty BS, Singh V, et al. Durable bonds at the adhesive/dentin interface: an impossible mission or simply a moving target? Braz Dent Sci 2012;15:4-18. 
[2] Barcellos DC, Batista GR, Silva MA, Pleffken PR, Rangel PM, Fernandes Jr VV, et al. Two-year clinical performance of self-etching adhesive systems in composite restorations of anterior teeth. Oper Dent 2013;38(3):258-66.

[3] Spencer P, Ye Q Misra A, Goncalves SE, Laurence JS. Proteins, pathogens, and failure at the composite-tooth interface. J Dent Res 2014 Dec;93(12):1243-9.

[4] Neri JR, Yamauti M, Feitosa VP, Pires APM, Araújo RS, Santiago SL. Physicochemical properties of a methacrylate-based dental adhesive incorporated with epigallocatechin-3-gallate. Braz Dent J 2014;25(6):528-31.

[5] Toledano M, Yamauti M, Ruiz-Requena ME, Osorio R. A $\mathrm{ZnO}$-doped adhesive reduced collagen degradation favouring dentine remineralization. J Dent 2012;40(9):756-65.

[6] Carrilho MR, Tay FR, Donnelly AM, Agee KA, Tjaderhane L, Mazzoni A, et al. Host-derived loss of dentin matrix stiffness associated with solubilization of collagen. J Biomater Res B: Appl Biol 2009;90:373-80.

[7] Toledano M, Sauro S, Cabello I, Watson T, Osorio R. A $\mathrm{Zn}$-doped etch-and-rinse adhesive may improve the mechanical properties and the integrity at the bonded-dentin interface. Dent Mater 2013;29(8):e142-52.

[8] Osorio R, Yamauti M, Osorio E, San Román J, Toledano M. Zinc-doped dentin adhesive for collagen protection at the hybrid layer. Eur J Oral Sci 2011;119:401-10.

[9] Tezvergil-Mutluay A, Agee KA, Hoshika T, Tay FR, Pashley DH. The inhibitory effect of polyvinylphosphonic acid on functional matrix metalloproteinase activities in human demineralized dentin. Acta Biomater 2010;6(10):4136-42.

[10] Santos MCLG, Souza AP, Gerlach RF, Tabchoury CM, Line SRP. Inhibition of human gelatinises (matrix metalloproteinase-2 and matrix metalloproteinase-9) activity by zinc oxide: a possible mechanism to enhance wound healing. $\mathrm{Br} J$ Dermatol 2001;145:838-58.

[11] Atsuo I, Haruo K, Makoto O, Masako I, Hajime O, Kunio I, et al. Zinc-releasing calcium phosphate for stimulating bone formation. Mater Sci Eng C 2002:22.

[12] Osorio R, Yamauti M, Osorio E, Ruiz-Requena ME, Pashley $\mathrm{DH}$, Tay FR, et al. Zinc reduces collagen degradation in demineralized human dentin explants. J Dent 2011;39:148-53.

[13] Takatsuka T, Tanaka K, Lijima Y. Inhibition of dentin demineralization by zinc oxide: in vitro and in situ studies. Dent Mater 2005;21:1170-80.

[14] Lynch RJ, Churchley D, Butler A, Kearns S, Thomas GV, Badrock TC, et al. Effects of zinc and fluoride on the remineralisation of artificial carious lesions under simulated plaque fluid conditions. Caries Res 2011;45(3):313-22.

[15] Wang Y, Spencer P, Yao X, Ye Q. Effect of coinitiator and water on the photoreactivity and photopolymerization of HEMA/camphoquinone-based reactant mixtures. J Biomed Mater Res A 2006 Sep 15;78(4):721-8.

[16] Marimoto AK, Cunha LA, Yui KC, Huhtala MF, Barcellos DC, Prakki A, et al. Influence of Nd:YAG laser on the bond strength of self-etching and conventional adhesive systems to dental hard tissues. Oper Dent 2013;38(4):447-55.

[17] Pallan S, Furtado Araujo MV, Cilli R, Prakki A. Mechanical properties and characteristics of developmental copolymers incorporating catechin or chlorhexidine. Dent Mater 2012;28(6):687-94.

[18] Prakki A, Pereira PN, Kalachandra S. Effect of propionaldehyde or 2,3-butanedione additives on the mechanical properties of Bis-GMA analog-based composites. Dent Mater 2009;25(1):26-32.

[19] Peralta SL, Carvalho PHA, van de Sande FH, Pereira CMP, Piva E, Lund G. Self-etching dental adhesive containing a natural essential oil: anti-biofouling performance and mechanical properties. Biofouling 2013;29(4):345-55.
[20] Cavalcanti BN, Rode SM, Marques MM. Cytotoxicity of substances leached or dissolved from pulp capping materials. Int Endod J 2005;38(8):505-9.

[21] Koulaouzidou EA, Helvatjoglu-Antoniades M, Palaghias G, Karanika-Kouma A, Antoniades D. Cytotoxicity of dental adhesives in vitro. Eur J Dent 2009;3(1):3-9.

[22] Bonaventura P, Benedetti G, Albarède F, Miossec P. Zinc and its role in immunity and inflammation. Autoimmun Rev 2015;14(4):277-85.

[23] Memarzadeh K, Sharili AS, Huang J, Rawlinson SC, Allaker RP. Nanoparticulate zinc oxide as a coating material for orthopedic and dental implants. J Biomed Mater Res A 2015;103(3):981-9.

[24] Toledano M, Aguilera FS, Osorio E, Cabello I, Toledano-Osorio M, Osorio R. Bond strength and bioactivity of Zn-doped dental adhesives promoted by load cycling. Microsc Microanal 2015 Feb;21(1):214-30.

[25] Hojati Tavassoli, Alaghemand H, Hamze F, Ahmadian Babaki F, Rajab-Nia R, Rezvani MB, et al. Antibacterial, physical and mechanical properties of flowable resin composites containing zinc oxide nanoparticles. Dent Mater 2013;29:495-505.

[26] Guerreiro-Tanomaru JM, Trindade-Junior A, Costa BC, da Silva GF, Drullis Cifali L, Basso Bernardi MI, et al. Effect of zirconium oxide and zinc oxide nanoparticles on physicochemical properties and antibiofilm activity of a calcium silicate-based material. Scientific World J 2014;2014:975213.

[27] Wang ZL. Nanostructures of zinc oxide. Mater Today 2004;7(6):26-33.

[28] Zhang Z, Ram MK, Stefanakos EK, Goswami DY. Synthesis, characterization, and applications of $\mathrm{ZnO}$ nanowires. J Nanomater 2012;2012.

[29] Souza AP, Gerlach RF, Line SRP. Inhibition of human gingival gelatinases (MMP-2 and MMP-9) by metal salts. Dent Mater 2000;16:103-8.

[30] Scheffel DL, Hebling J, Scheffel RH, Agee K, Turco G, de Souza Costa CA, et al. Inactivation of matrix-bound matrix metalloproteinases by cross-linking agents in acid-etched dentin. Oper Dent 2014;39(2):152-8.

[31] Zhang SC, Kern M. The role of host-derived dentinal matrix metalloproteinases in reducing dentin bonding of resin adhesives. Int J Oral Sci 2009;1(4):163-76.

[32] Stanislawczuk R, Reis A, Loguercio AD. A 2-year in vitro evaluation of a chlorhexidine-containing acid on the durability of resin-dentin interfaces. J Dent 2011;39(1):40-7.

[33] Montagner AF, Sarkis-Onofre R, Pereira-Cenci T, Cenci MS. MMP inhibitors on dentin stability: a systematic review and meta-analysis. J Dent Res 2014;93(8):733-43.

[34] Pashley DH, Tay FR, Yiu C, Hashimoto M, Breschi L, Carvalho RM, et al. Collagen degradation by host-derived enzymes during aging. J Dent Res 2004;83(3):216-21.

[35] Carvalho RV, Ogliari FA, de Souza AP, Silva AF, Petzhold CL, Line SR, et al. 2-hydroxyethyl methacrylate as an inhibitor of matrix metalloproteinase-2. Eur J Oral Sci 2009;117(1):64-7.

[36] Mazzoni A, Nascimento FD, Carrilho M, Tersariol I, Papa V, Tjäderhane L, et al. MMP activity in the hybrid layer detected with in situ zymography. J Dent Res 2012;91(5):467-72.

[37] Henn S, de Carvalho RV, Ogliari FA, de Souza AP, Line SR, da Silva AF, et al. Addition of zinc methacrylate in dental polymers: MMP-2 inhibition and ultimate tensile strength evaluation. Clin Oral Investig 2012;16(2):531-6.

[38] Park JG, Ye Q, Topp EM, Misra A, Spencer P. Water sorption and dynamic mechanical properties of dentin adhesives with a urethane-based multifunctional methacrylate monomer. Dent Mater 2009;25(December (12)):1569-75.

[39] Singh V, Misra A, Parthasarathy R, Ye Q, Park J, Spencer P. Mechanical properties of methacrylate-based model dentin 
adhesives: effect of loading rate and moisture exposure. J Biomed Mater Res B: Appl Biomater 2013;101(November (8)):1437-43.

[40] Solhi L, Atai M, Nodehi A, Imani MA. novel dentin bonding system containing poly(methacrylic acid) grafted nanoclay: synthesis, characterization and properties. Dent Mater 2012;28(October (10)):1041-50.

[41] Peutzfeldt A, Asmussen E. Modulus of resilience as predictor for clinical wear of restorative resins. Dent Mater 1992;8(3):146-8.

[42] Li ZC, White SN. Mechanical properties of dental luting cements. J Prosthet Dent 1999;81(5):597-609.

[43] Suzuki S, Ori T, Saimi Y. Effects of filler composition on flexibility of microfilled resin composite. J Biomed Mater Res B: Appl Biomater 2005;74(1):547-52.

[44] Davidson CL. Resisting the curing contraction with adhesive composites. J Prosthet Dent 1986;55(4):446-7.

[45] Suh BI. Controlling and understanding the polymerization shrinkage-induced stresses in light-cured composites. Compend Contin Educ Dent Suppl 1999;25:S34-41.
[46] Condon JR, Ferracane JL. Reduction of composite contraction stress through non-bonded microfiller particles. Dent Mater 1998;14(4):256-60.

[47] Condon JR, Ferracane JL. Assessing the effect of composite formulation on polymerization stress. J Am Dent Assoc 2000;131(4):497-503.

[48] Van Meerbeek B, Perdigão J, Lambrechts P, Vanherle G. The clinical performance of adhesives. J Dent 1998; 26(1):1-20

[49] Ratanasathien S, Wataha JC, Hanks CT, Dennison JB. Cytotoxic interactive effects of dentin bonding components on mouse fibroblasts. J Dent Res 1995;74(9):1602-6.

[50] Kaga M, Seale NS, Hanawa T, Ferracane JL, Waite DE, Okabe T. Cytotoxicity of amalgams, alloys, and their elements and phases. Dent Mater 1991;7(1):68-72.

[51] Saha N, Dubey AK, Basu B. Cellular proliferation, cellular viability, and biocompatibility of HA-ZnO composites. J Biomed Mater Res B: Appl Biomater 2012;100(1):256-64. 